\title{
Trial Use of Inquiry Methods in Learning to Write Arabic in Junior High School Santi Asromo Majalengka
}

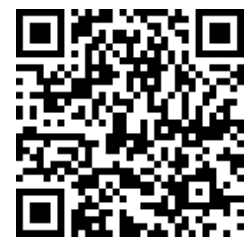

\section{Alsuna: Journal of Arabic and English Language}

Ade Arip Ardiansyah

Universitas Islam Negeri Sunan

Gunung Djati

8

adearipardiansyah94@gmail.com

\section{Keywords:}

Inquiry method

Writing Arabic skills

Santi Asromo Majalengka (Junior high school)

\section{Article Information:}

Submitted: May 18, 2020

Accepted: May 20, 2020

Approved: June 01, 2020

\section{Abstract}

Purpose - This study aims to test the ability of students when learning Arabic writing skills both after and before using survey methods.

Design/methodology/approach - Because it aims to test effectiveness, researchers use quantitative-experimental methods with one group pre-test and post-test design. While the research object used as a sample is 8th grade students at Santi Asromo Majalengka Middle School.

Findings - The findings from the results of this study are, there are significant changes when learning to write using survey methods. With the details of $t$-count greater than $t$-table with an error level of $5 \%$ and the level of effectiveness is at the level of 53\%.

Originality/value - The implication of the results of this experiment is that teaching in the post method era does not mean eliminating a method in teaching. Furthermore, what will become a reflection for further research is how to position the method in the e-learning era and apply a method in it.

Paper type - Research Paper

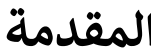

كان تدريس اللغة العربية في الماضى مجرد على تعميق فهم الشريعة الإسلامية في القرآن والحديث.

لذالك، فهم اللغة العربية وتدريسها من أمر ضرورى. وهذاليوم، معظم اتِّاه تدريس اللغة العربية يتطور، و يقوم بتدرسها جميع المدارس والمعاهد والجامعات الإسلامية (Izzan 2012). والأغراض الأسـاسية من تعلّم اللغة العربية لتكشيف و تطوير قدرة التلاميذ على الاستعمال اللغة شفاهيا كان أو تحريريا ( Wahab

كما هو المعروف أن اللغة العربية لها أربع مهارات، وهي مهارة الإستماع و مهارة الكلام و مهارة القراءة و مهارة الكتابة (Mufidah et al). أما أغراضها فهي: ()). مهاراة الإستماع أن تدرب إلى أي مدى يستطيع التلاميذ أن يلاحظوا أو يستمعون إلى ما يسمع لهه. يشمل الأصوات والجمل والمحتويات وغيرها، سيكون

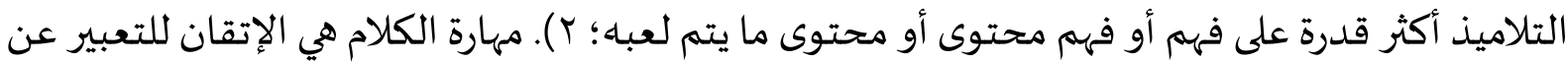
الأفكار والخبرات من خلال اللغة اللفظية. لتحقيق هذا الهدف، هناك حاجة إلى عملية التدريب؛ ؟). مهارة 


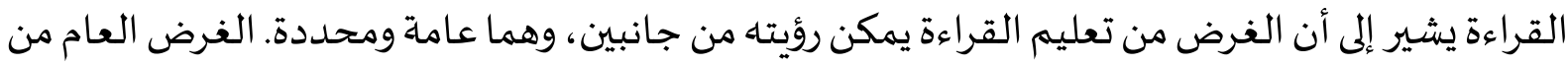

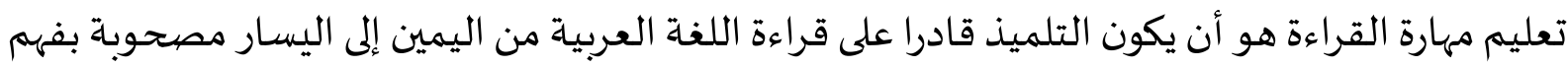
جيد؛ §).مهارة الكتابة، هناك جانبان من القدرات التي يجب تطويرها، وهما القدرة الفنية وقدرة الإبداعية.

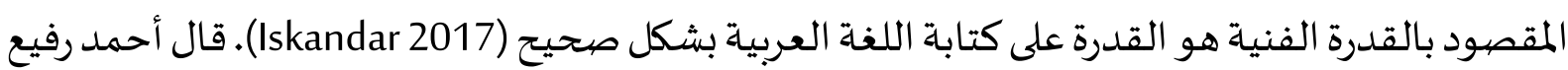

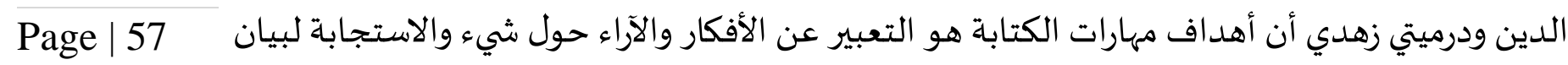

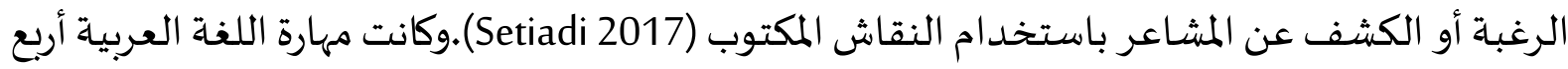

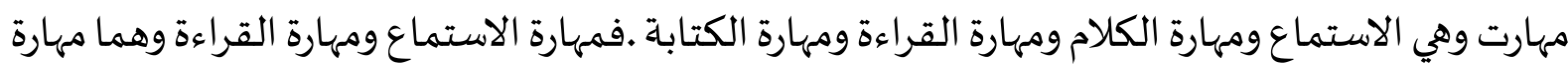
استقبالية وأمامهارة الكلام ومهارة الكتابة فهماومهارة انتاجية (Hermawan 2018b).

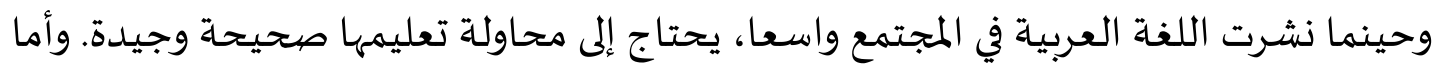

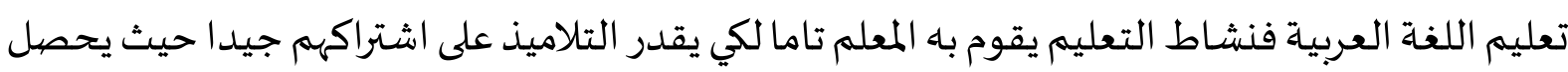

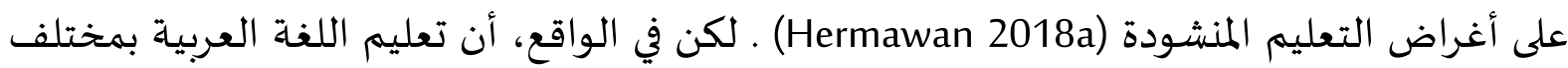

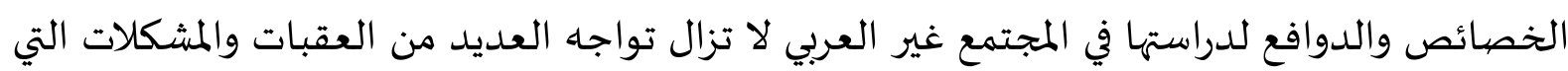

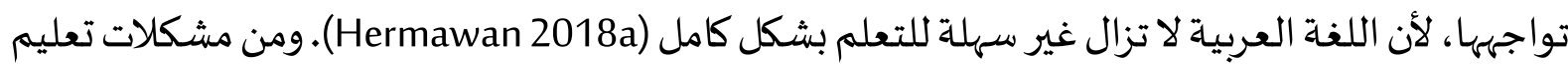

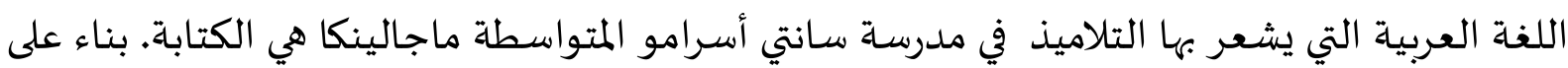

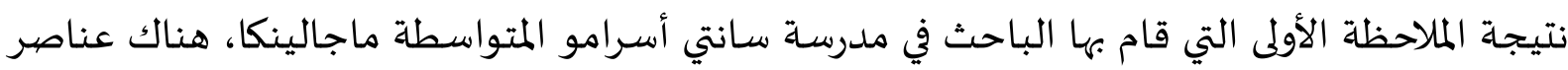

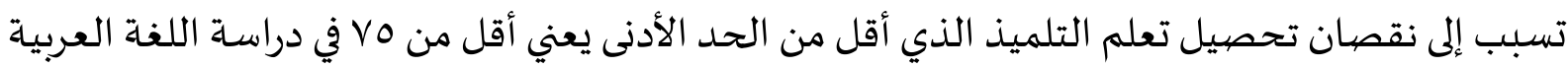

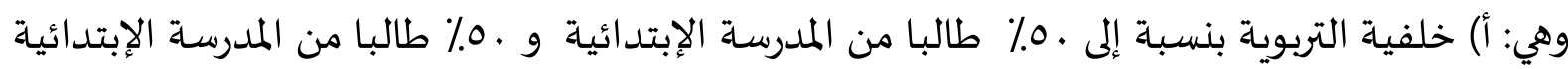

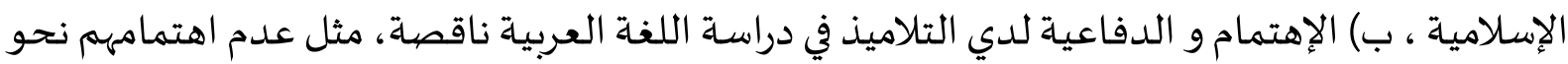

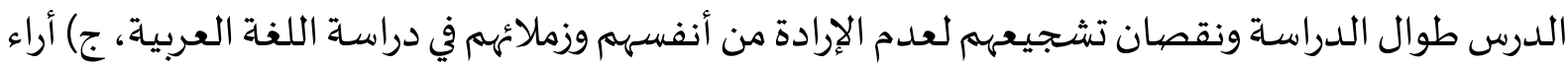

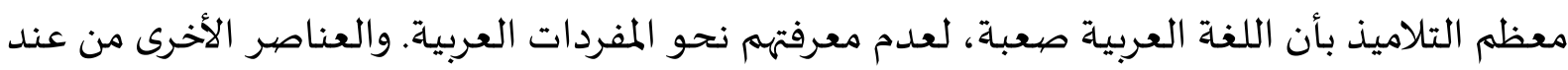
المدرس نفساه، يعني عدم استخدام وسائل الإيضاح المطابقة، وهذا تسبب إلى صعوبة الطالب في فهم المادة المادية بل هم سائمون في اشتراك الدراسة، وكذلك طريقة التدريس الرتيبة تجعلهم سلبيا في التعلم.

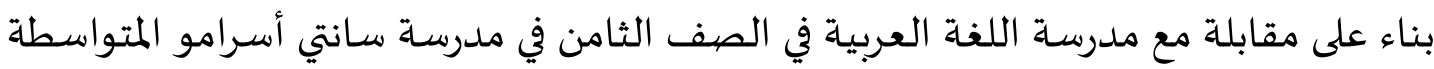

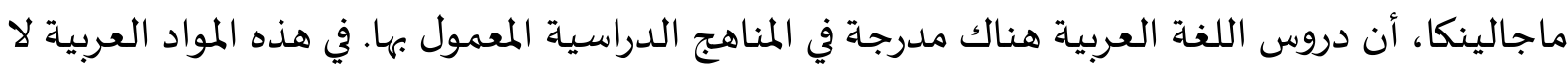

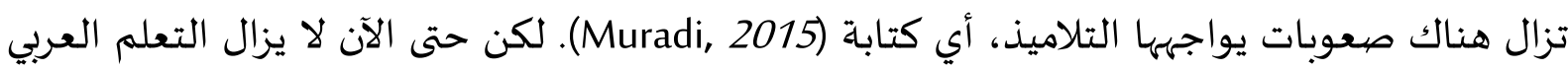

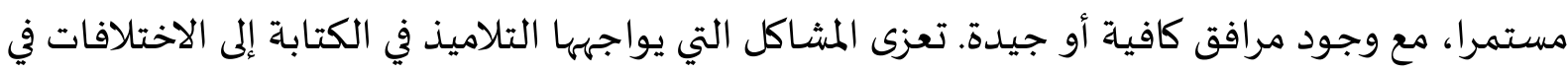

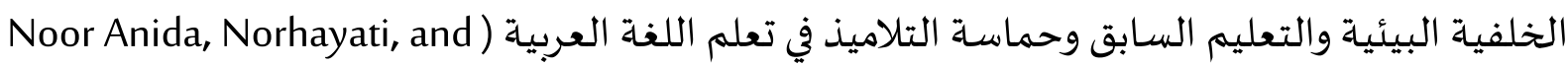

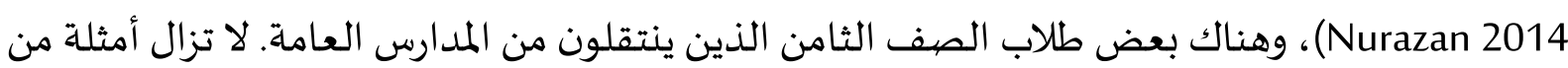

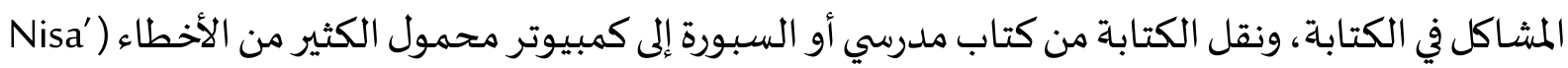

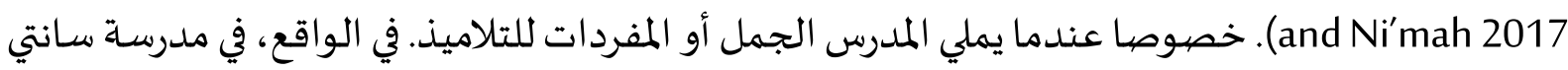


أسرامو المتواسطة ماجالينكا عندما يكونون خارج أنشطة التعليم والتعلم، فإنهم يتلقون أيضيا أنشطة يومية

تقرببا تتعلق بالعربية. المقدمة من مسؤولي مجلس الإدارة من خلال الكتابة على لوحة أو لفظيا فقط.

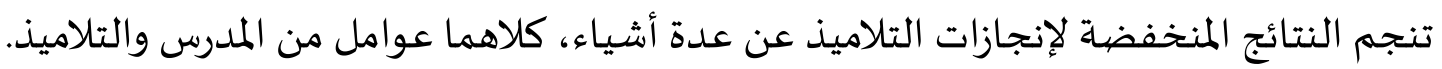

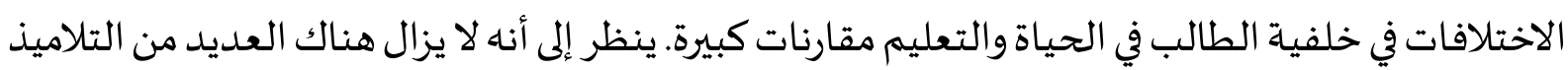
الذين لم يجيدوا كتابة رسائل الحجيج مع مدى ملاءمة حرف مخرج. يستخدم المدرس طريقة بسيطة في تعلم

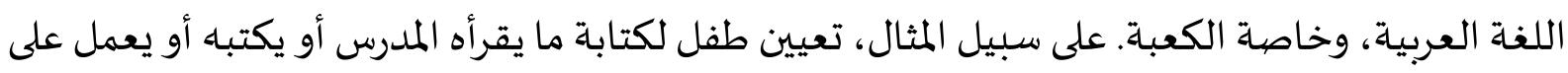
أسئلة الممارسة وكتابة قراءة وكتابة نظرة عامة على الدروس المستفادة من مهاراته اللغوية (Rofian et al).

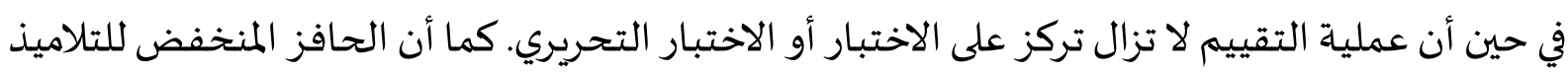

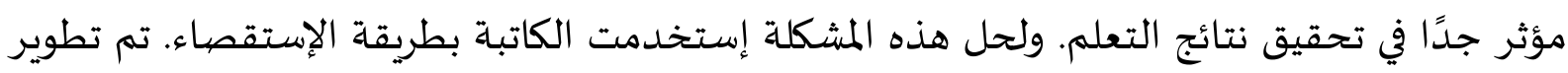
طريقة التعلم هذه بواسطة شخصية تسمى سوخمان. يعتقد سوخمان أن الأطفال هم أفراد لديهم فضيول كول كل شيء. منذ أن ولد البشر في العالم ، فإن البشر لديهم الرغبة في العثور على معارفهم الخاصة ( Sitti

.(Kuraedah 2015

\section{طريقة البحث}

أما الطريقة التي تستخدم في هذا البحث هي طريقة شباه تجربة بتصيميم مجموعاة واحدة الاختبار القبلي و الاختبار في المجموعة الواحدة أساليب جمع البيانات. هذا التصميم هو الاختبار القبلي قبل إعطاء

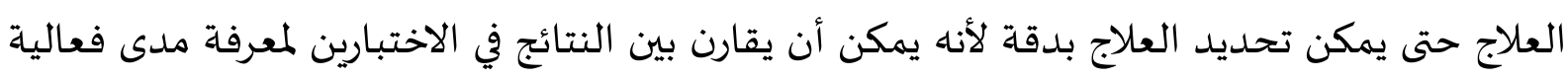

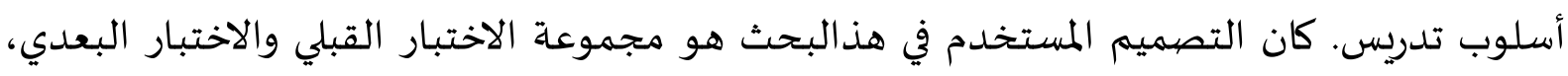
تستخدم هذالبحث عينة دراسة واحدة فقط، وهي الفصل التجريبي بدون الفصل التحكيمي وهناك الاختبار القبلي. وأما البيانات في هذا البحث فهي التلاميذفي الصف الثامن في مدرسة سانتي أسرامو المتواسطة ماجالينكا. أما العينة في هذا البحث فهي جميع التلاميذ في الصف الثامن "بمدرسـة "Junior "High School Santi Asromo Majalengka بعدما جمعت البيانات المحتاجاة، فالخطوات التالية هي تحليلها. ويتم هذا التحليل بطريقين: (1) التحليل المنطقي (للبيانات النوعياة)، (Y) التحليل الإحصائي (للبيانات الكمية). يستخدم هذا البحث تحليل البيانات الكمية من نتيجة الاختبار القبلي والاختبار البعدي بتصيميم مجموعة واحدة.

\section{أحدث البحث وتميزه}

ومن البحوث السابقة التي تبحث عن هذه الطريقة منها بحث لـ (M. Chotibuddin 2019) وكان بحثـه عن استخدام الطريقة الإحصائية فى تعليم اللغة الإنجليزية. أما تطبيقها فقد قام الباحث في المرحلة المدرسة المتوسطة. وليس هناك تحديد أي المهارات في استخدامها. ثم التالي، البحث الذى قام باء (Bawamenewi 2018)، وكان بحثه عن استخدام الطريقة الإحصائية في تعليم الشعر الإندونيسي. وهناك أيضا البحوث عن تعليم الإندونيسية بالطريقة الإحصائية ، منهم (Fatmaira 2018)(Simamora and) 
وكان أكثر تخصص بحوثها ليست فى تعليم مهارة الكتابة. Pangaribuan 2017)(Arifien and Suniati 2018) ثم البحوث الأخرى فهو بحث (Kusrini and Rosita 2017)، في هذا البحث عن توصيف عملية تعليم اللغة الفرنسية بطريقة الإحصاء.

أما من المباحث من وجهة هذه المجلة العلمية، كان مباحث الطريقة التعليمية قد حدد على بحث

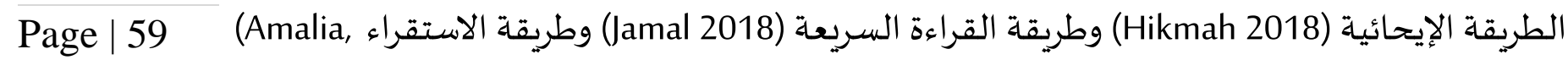
(Baidawi, and Aisyah 2019) تعليم الكتابة العربية. لأن الأهم من هذا، كان البحث في دور الكتابة العربية قد تكون نادرا جدا.

المناقشة

أن المعلم الذي لايعرف إلاّ طريقة واحدة لينجز بها هدفا من أهداف العمل التعليمي أو التربوي، يعتبر مدرسا معوّقا. قال ريتشـارد ستشمان أنّ التلاميذ الذين دربوا بطريقة الاستقصاء، يسألون أسئلة تزيد

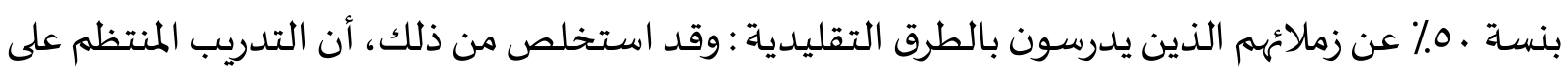
الاستقصاء ينمي الثقة بالذات (Huda 2016). ويمكننا معرفة قيمة وأهمية الاستقصياء بمقارنته بالتدريس التقليدي. وبالاضافة إلى طريقة الاستقصاء من خلال استخدام الوسائط المصورة في مهاراة الكتابة لدعوة التلاميذ مباشرة إلى العملية العلمياة، بالإضـافة إلى ذلك، يمكن أن تساعد تمارين الاستقصاء على تحسين فهم التلاميذ في حل المشكلات

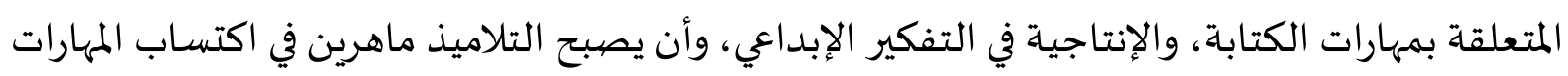

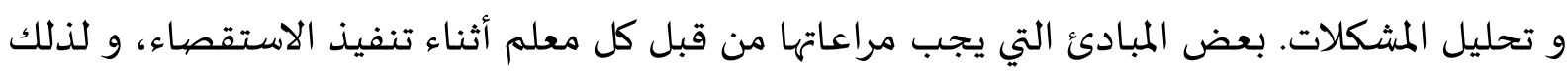

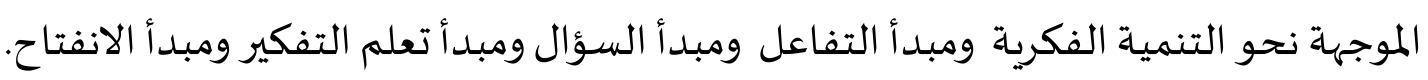

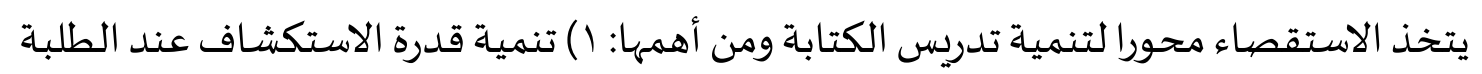

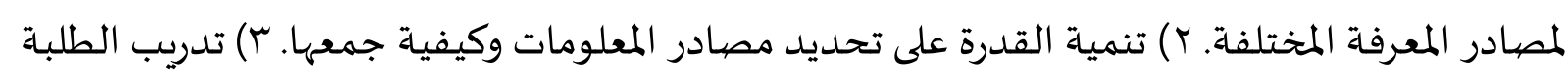
على اتخاذ. ع) توفير الفرص للتطوير والتقدم وفقًا لقدراتهم واهتماماتهم. 0) يصبح وضع عملية التعلم أكثر تحفيزا (Thu'aimah 2010)و(Hanifah 2016). وتحتاج هذه الطريقة إلى مزيد من العطاء من معلم لعرض

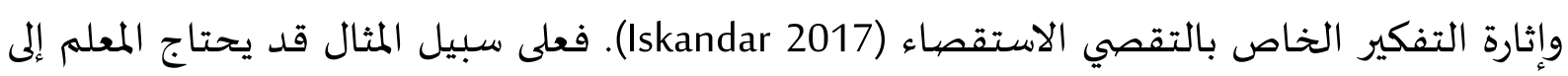

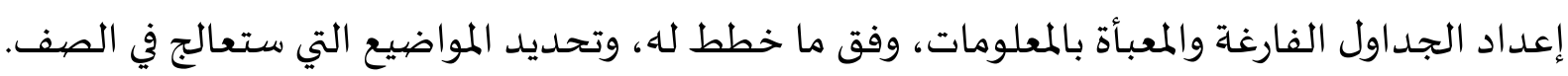

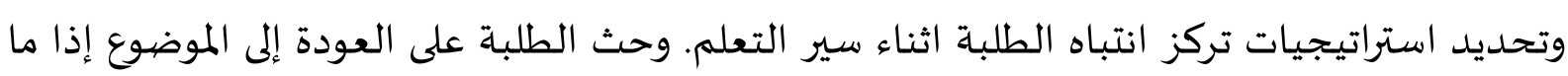

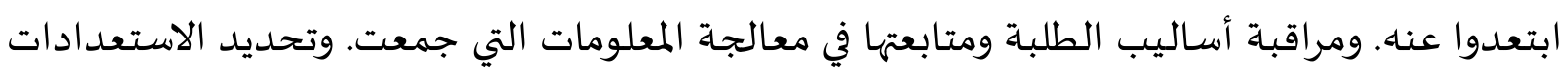

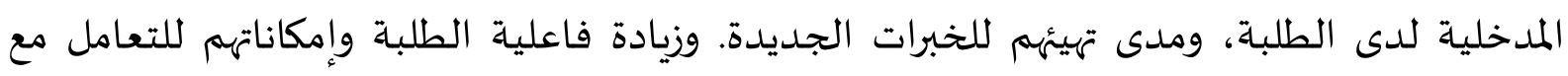
المعلومات ومعالجتها وفهمها (Hasyim and Marzun R 2018). 
بناء على خطوات التعليم، يعد طريقة الاستقصاء مناسبا جدا لإستخداماه في تعليم مهارة الكتابة. وبالاضيافة إلى طريقة الاستقصاء من خلال استخدام الوسائط المصورة في مهاراة الكتابة لدعوة التلاميذ

\section{صياغة المشاكل التي يتم استخداهما كمواضيع في تعليم الكتابة}

Page $\mid 60$

$$
\text { • يسأل المعلم سؤالا أوليا حول المشكلة التي تم تعيينها، ثم سيقوم الطالب بطرح سؤال }
$$

\section{جمع البيانات من خلال المراقبة}

• قراءة المواد وتحديدها للحصول على معلومات متنوعة مثل البيانات الداعمة.

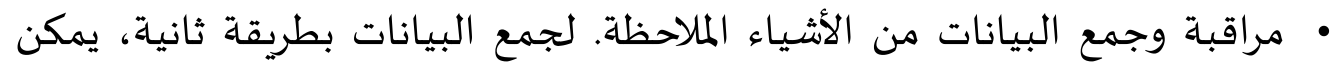

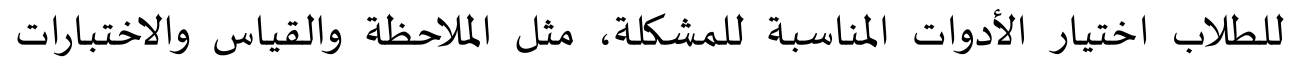

$$
\text { والمقابلات وما إلى ذلك احتبار الكوات }
$$

\section{يمكن القيام بالخطوة الثالثة على مرحلتين}

• تحليل ومناقشاة البيانات الموجودة والمعدلة حسب البيانات الداعمة وإيجاد حل.

$$
\text { • استخلص النتائج بناء على المناقشاة. }
$$

\section{تو صييل المشناكلات التي تمت صياغتها وحلما بشكل مكتوب.}

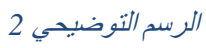

مباشرة إلى العملية العلمية، بالإضافة إلى ذلك، يمكن أن تساعد تمارين الاستقصاء على تحسين فهم

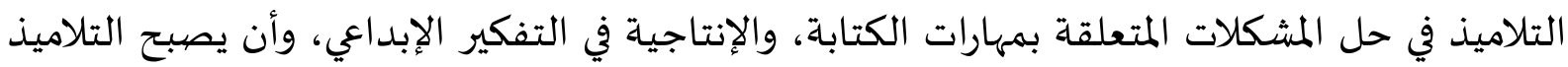
ماهرين في اكتساب المهارات و تحليل المشكلات. بعض المبادئ التي يجب مراعاتها من قبل كل معلم أثناء تنفيذ الاستقصاء، و لذلك الموجهة نحو التنمية الفكرية ومبدأ التفاعل ومبدأ السؤال ومبدأ تعلم التفكير ومبدأ الانفتاح (Husin 2014).

في كل مجموعاة، قدرة التلاميذ تطوير القدرة على التفكير الإبداعي مع تحقيق أعلى النتائج في جوانب بناء المفاهيم فوق المعرفة الموجودة لدى التلاميذ والأقل في جانب اختيار الأشياء التي قد لا تكون ذات صلة، وكذلك المهارات في عمليات العلوم. والغرض من التعلم التعلم في الكتابة التعلم هو (Ratnaningtyas 2015) : ( ) قادرة على حل المشاكل التي تواجهها في الحياة اليومية باستخدام المفاهيم

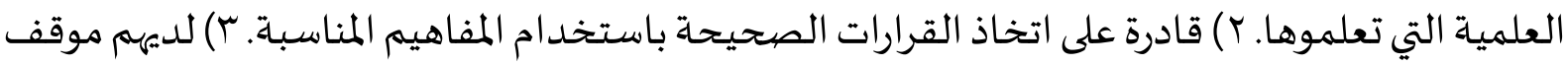
علمي في حل المشكلات التي تواجههم حتى يتمكنوا من التفكير والتصرف العلمي. بحيث يمكن زيادة مخرجات تعلم الطالب و تحقيق أهداف التعليم. أن قيمة المتوسط المحصولة قبل استخدام طريقة الإستقصاء في تعليم اللغة العربية لمادة الكتابة للفصل الثامن"ب" مدرسة سانتي أسرامو المتواسطة ماجالينكا تدل على درجة كافية، فإن قيمة المتوسط المّاء على قدر اN،و09 وهي تقع بين وV في معيار التفسير. من هذه النتائج يمكن استنتاج أن قيمة المتوسط 
المحصولة قبل استخدام طريقة الإستقصاء في تعليم اللغة العربية لمادة الكتابة للفصل الثامن"ب" مدرسة

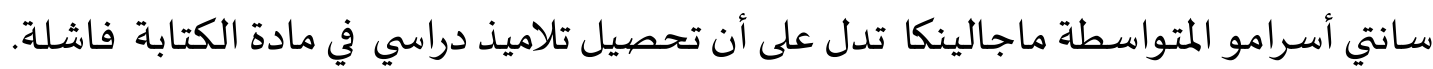

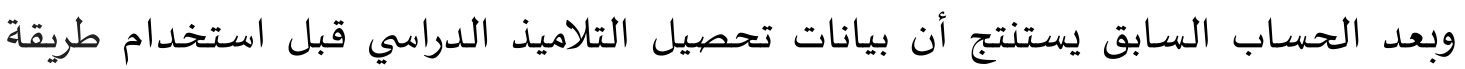

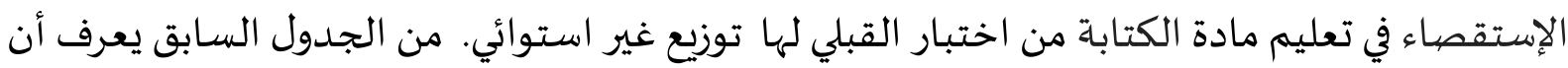

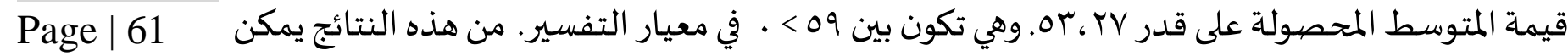

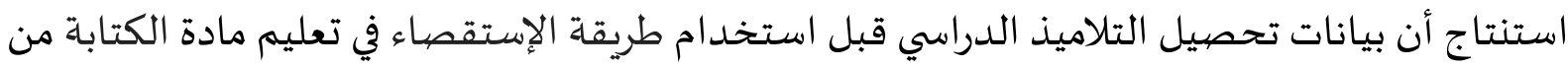
اختبار القبلي تدل على أن تحصيل تلاميذ دراسي في مادة الكتابة فاشلة التلات.

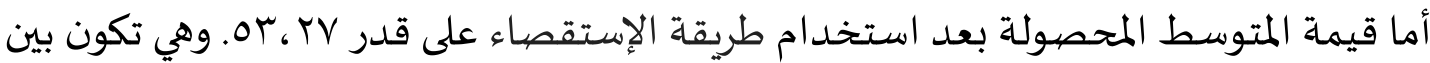

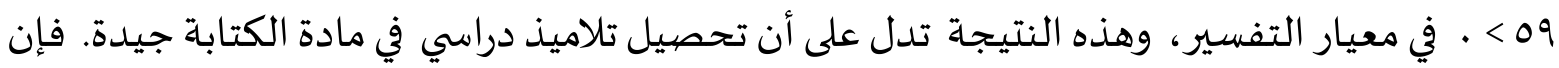

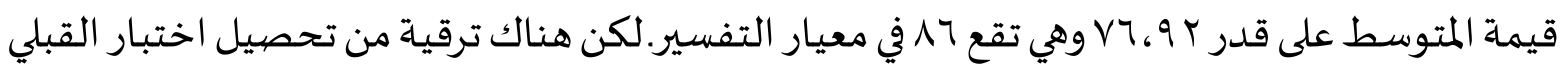

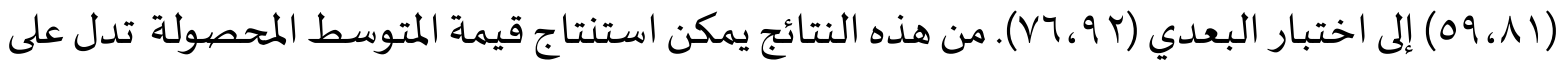

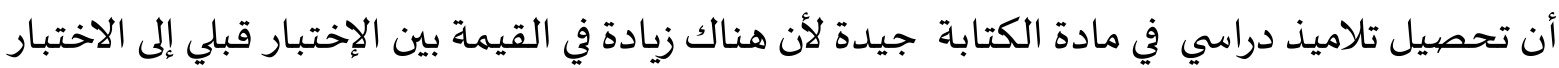
البعدي.

وبعد الحساب السابق يستنتج أن بيانات تحصيل التلاميذ الدراسي بعد استخدام طريقة

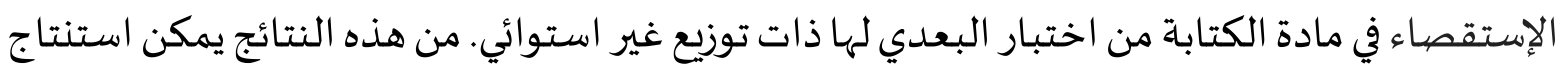

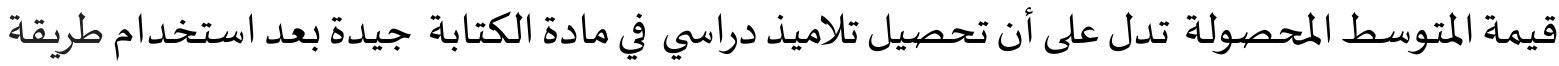
الإستقصاء في مادة الكتابة من اختبار البعدي لأن هناك زيادة في القيمة بين الإختبار قبلي إلى الئل الاختبار

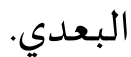

لمعرفة ترقية تحصيل تلاميذ الدراسي في مادة الكتابة بعد استخدام طريقاة الإستقصاء، فتبحث : عنها الباحث بامتحان المقارنة بالخطواط الآتية : 1. حساب جمع البيانات لترقية قدرة التلاميذ على الكتابة من الاختبار القبلي و الاختبار البعدي.

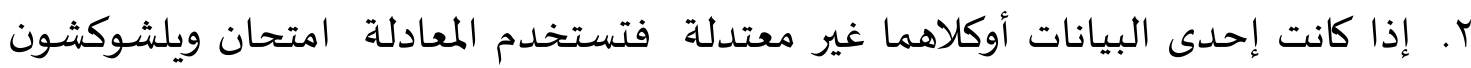

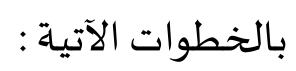

أن النتيجة من "'ز" الجدولية في اختبار طرفين

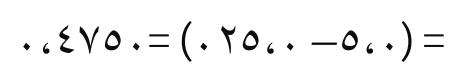

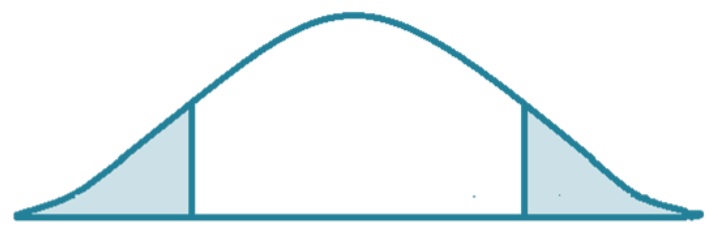

$1.97-\quad 1.97$ T. TH

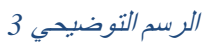


كما في الصورة السابقة أن قيمة "ز" سr،r في مجال الرفض HO H بمعنى أن هناك فرقا شديدا بين تحصيل تلاميذ الدراسي قبل استخدام طريقة الإستقصاء في مادة الكتابة وبعدها.

Page $\mid 62$

$$
\text { r. امتحان استواء البيانات (ن - د) }
$$

ولمعرفة ترقية النتيجة من الاختبار القبلي إلى الاختبار البعدي، تبحث عناه الباحث

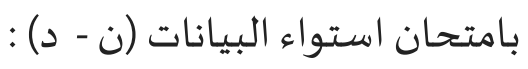

\begin{tabular}{|c|c|c|c|}
\hline نسبة مئوية & عدد التلميذ & تصنيف & معيار النتيجة ن - د \\
\hline$\%$ & . & مرتفع & $\cdot 6 r<$ \\
\hline$\%$ or & $1 \varepsilon$ & معتدل & $. r V \geq د>\cdot r r$ \\
\hline$\%$ \% & ir & منخفض & $. r \geq 2$ \\
\hline
\end{tabular}

من الجدول السابق يعرف أن التلاميذ الذين حصلوا على نتيجة V، ، إلى أعلى النتيجة

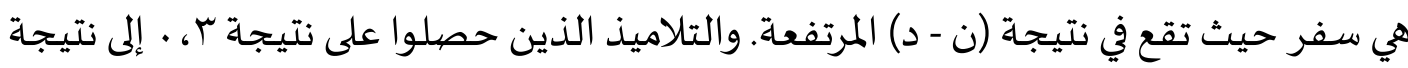

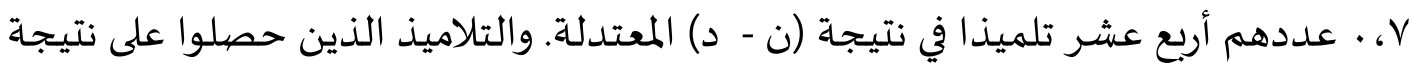

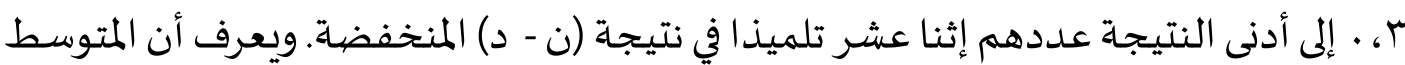

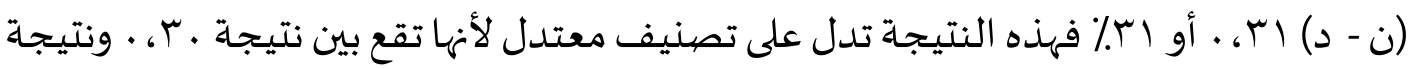

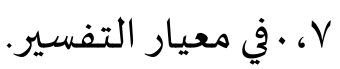
من هذه النتائج يمكن استنتاج النتيجة من الاختبار القبلي إلى الاختبار البعدي تدل على أن أن النائ

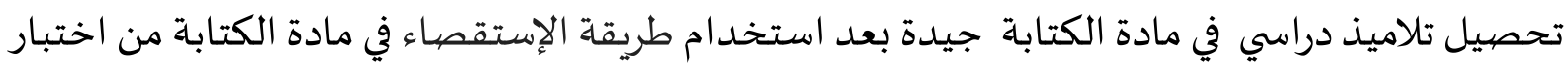

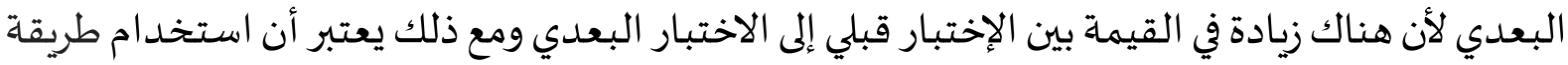

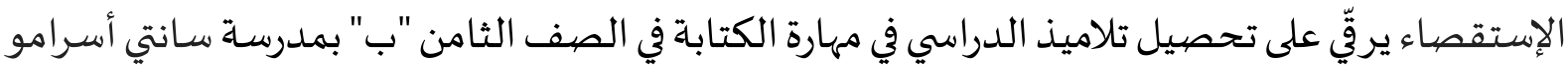
المتواسطة ماجالينكا. لذلك يفهم من الحساب أن الترقية من استخدام طريقة الإستقصاء في مادة الكتابة على تحصيل الدراسي آس، • أو آسا في طبقة معتدلة.

\section{الخلاصة}

وبعد اقام الكاتب بالبحث الكمي عن استخدام طريقة الإستقصاء في تعليم اللغة العربية لمادة

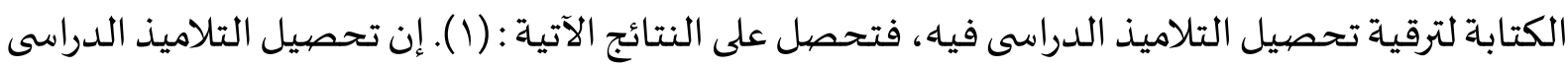

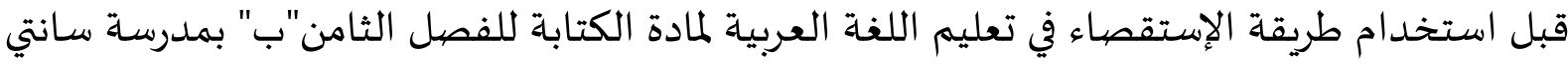

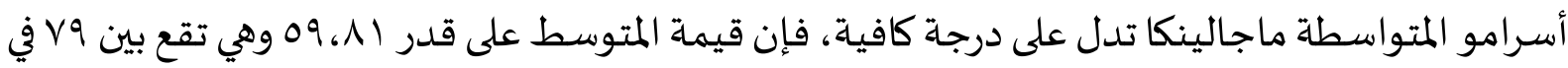
معيار التفسير؛ (Y). إن تحصيل التلاميذ الدراسى بعد استخدام طريقة الإستقصاء في تعليم اللغة العربية 
لمادة الكتابة للفصل الثامن بمدرسة سانتي أسرامو المتواسطة ماجالينكا تدل على درجة جيدة، فإن قيمة

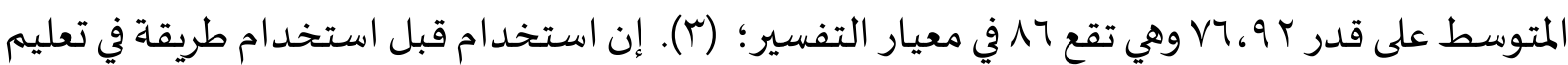
اللّغة العربية بمادة الكتابة يؤثر تأثيرا في ترقية قدرة التلاميذ على الكتابة. وهذا يتحقق بكون قيمة (ت)

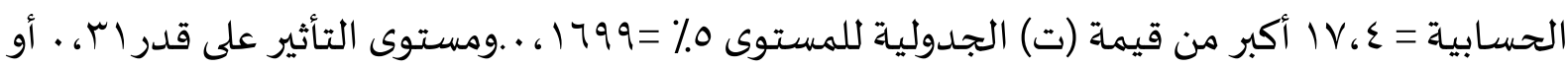

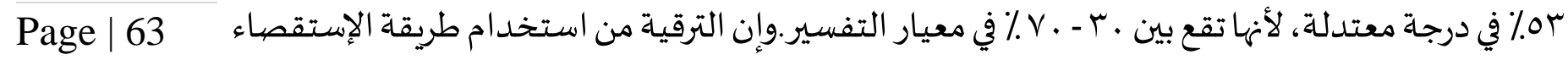

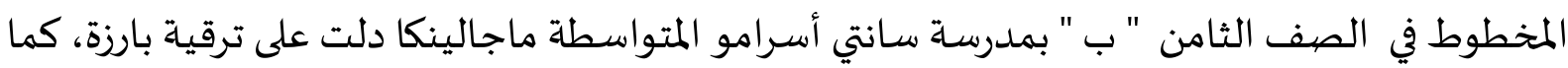
دلت عليه النتيجة من "ز" الجدولية في اختبار طرفين

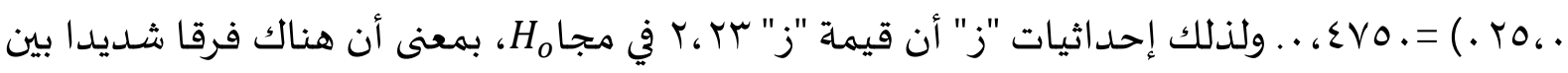
تحصيل تلاميذ الدراسي قبل استخدام طريقة الإستقصاء المخطوط في مادة الكتابة وبعدها. وأما نتيجة (ن-

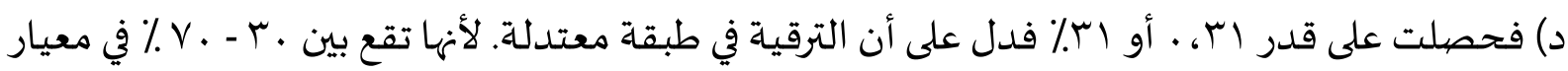

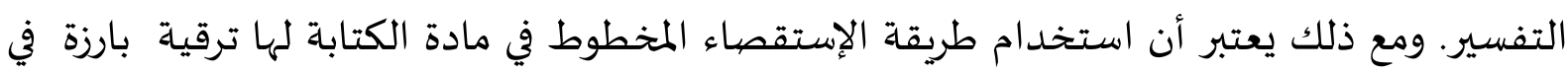
تحصيل تلاميذ الدراسي في الصف الثامن"ب" بمدرسة سانتي أسرامو المتواسطة ماجالينكا.

اللاستفادة

في نهاية هذا العقد، هو قرن حيث لم يعد التعلم يعتمد على الأسـاليب أو يشار إليه عادة باسم عصر ما بعد الطريقة، بالإضافة إلى تعلم اللغات الأجنبية لغير المتحدثين. من الضروري فقط أن تعرف أنها

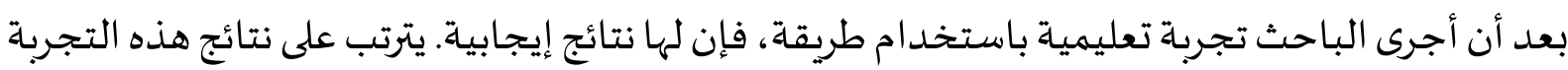
أن التدريس في عصر ما بعد الطريقة لا يعني القضاء على طرق التدريس. علاوة على ذلك، ما سيصبح انعكاسًا لمزيد من البحث هو كيفية وضع الأسـاليب في عصر التعلم الإلكتروني وتطبيق الأسـاليب فيها.

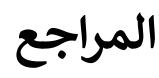

Amalia, Dian Risky, Ahmad Baidawi, and Nurul Aisyah. 2019. "Ta'thīr Tațbīq Thariqah Al-Istiqrā' Fi as-Sayțarah 'alā Al-Qawā'id an-Naḥwiyyah Ladā Talāmīdh Al-Fașl Al-Thāmin Bi Madrasah Dār Al-A'māl Al-Thanawiyyah Al-Islāmiyyah Metro." Alsuna: Journal of Arabic and English Language 2 (2): 164-77. https://doi.org/10.31538/alsuna.v2i2.390.

Arifien, Helpy Patriana, and Suniati Suniati. 2018. "Peningkatan Hasil Belajar Bahasa Indonesia Menggunakan Metode Inkuiri Dengan Media Konkret Pada Peserta Didik Palangkaraya." Tunas: Jurnal Pendidikan Guru Sekolah Dasar 4 (1): 32-40. https://doi.org/10.33084/tunas.v4i1.499.

Bawamenewi, Arozatulo. 2018. "KEMAMPUAN MENULIS PUISI BEBAS DENGAN MENERAPKAN METODE INKUIRI TERHADAP SISWA SMP NEGERI 3 GUNUNGSITOLI." JURNAL PENELITIAN PENDIDIKAN BAHASA DAN SASTRA 3 (2): 333-38. https://doi.org/10.32696/ojs.v3i2.180.

Fatmaira, Zira. 2018. "PENGARUH MODELPEMBELAJARAN INKUIRI TERHADAP KEMAMPUAN MENEMUKAN UNSUR KEBAHASAAN TEKS CERITA FABEL OLEH SISWA KELAS VIII SMP NEGERI 3 BINJAI." EDUKASI KULTURA : JURNAL BAHASA, SASTRA DAN BUDAYA 1 (2). 
https://doi.org/10.24114/kultura.v1i2.11728.

Hanifah, Umi. 2016. "PENERAPAN MODEL PAIKEM Dengan MENGGUNAKAN MEDIA PERMAINAN BAHASA Dalam PEMBELAJARAN BAHASA ARAB." IImu Tarbiyah "At-Tajdid."

Hasyim, Syarifuddin, and DII. Marzun R. 2018. "Ta'lim Al Muhadatsah Li Tarqiyati Qudrot Al Tholabah 'Ala Al Takallum Bi Al Lughoh Al 'Arabiyah Bi Ma'Had Bab Al Najah Al 'Asry Banda Aceh." Jurnal Lisanuna 8 (2).

Hermawan, Acep. 2018a. Metodologi Pembelajaran Bahasa Arab. 4th ed. Bandung: PT Remaja Rosakarya.

- - . 2018b. Pembelajaran Keterampilan Berbahasa Arab Dengan Pendekatan KomunikatifInteraktif. Bandung: PT Remaja Rosakarya.

Hikmah, Hikmah. 2018. "Taḥlīl Ta'līm Al-Istimā’ Bi Al-Thariqah Al-Ịhā'iyyah Ladā Thalabah Markaz Al-Lughāt Jāmi'ah Sulthān Sharīf Qāsim Al-Islāmiyyah Al-Ḥukūmiyah Riau." Alsuna: Journal of Arabic and English Language 1 (1): 40-49. https://doi.org/10.31538/alsuna.v1i1.49.

Huda, Nurul. 2016. "KOMPONEN-KOMPONEN PEMBELAJARAN AL-KITÂBAH BAHASA ARAB." Al Mahāra: Jurnal Pendidikan Bahasa Arab. https://doi.org/10.14421/almahara.2016.021-01.

Husin, Normah Binti. 2014. "Analisa Kesalahan Pelajar Dalam Penulisan Bahasa Arab: Menulis Resume." In International Research Management and Innovation Conference.

Iskandar, Muhammad Lutfiana. 2017. "STRATEGI PEMBELAJARAN MENULIS (KITABAH) BAHASA ARAB." Jurnal Ilmiah Mahasiswa Raushan Fikr. https://doi.org/10.24090/jimrf.v6i1.2712.

Izzan, Ahmad. 2012. Metodologi Pembelajaran Bahasa Arab. Bandung: HUMANIORA.

Jamal, Mardhiana. 2018. "Tațbīq Ṭarīqah Al-Qirā’ah Al-Sarīah Fī Ta'līm Mahārah Al-Qirā'ah Li Al-Banāt Bi Ma'had Dār Al-Abrār Bonne." Alsuna: Journal of Arabic and English Language 1 (1): 50-58. https://doi.org/10.31538/alsuna.v1i1.65.

Kusrini, Nani, and Diana Rosita. 2017. "Peningkatan Penguasaan Tata Bahasa Prancis Mahasiswa Melalui Model Inkuiri." Jurnal Pendidikan Progresif 7 (2): 106-16. https://doi.org/10.23960/jpp.v7.i2.201714.

M. Chotibuddin. 2019. "Penggunaan Metode Inkuiri Dalam Peningkatan Hasil Belajar Bahasa Inggris Di Kelas Vii Madrasah Tsanawiyah Muhammadiyah 17 Paciran." Jurnal Pendidikan Islam 3 (2): 2-11. https://doi.org/10.37286/ojs.v3i2.38.

Mufidah, Nuril, Dessy Suryawati, Nihayatus Sa'adah, and Saidna Zulfiqar Bin Tahir. 2019. "LEARNING ARABIC WRITING SKILL BASED ON DIGITAL PRODUCTS." Ijaz Arabi Journal of Arabic Learning. https://doi.org/10.18860/ijazarabi.v2i2.8395.

Muradi, Ahmad. 2015. Pembelajaran Menulis Bahasa Arab Dalam Perspektif Komunikatif. 
Jakarta: Kencana Pustaka.

Nisa', Dwi Khoirotun, and Jauharotun Ni'mah. 2017. "PENGEMBANGAN BAHAN AJAR MAHĀRAH AL-KITĀBAH BERBASIS PENDIDIKAN KARAKTER BAGI MAHASISWA PROGRAM STUDI PENDIDIKAN BAHASA ARAB STAI ATTANWIR BOJONEGORO." Jurnal Al Bayan: Jurnal Jurusan Pendidikan Bahasa Arab. https://doi.org/10.24042/albayan.v9i1.1241.

Noor Anida, Awang, Che Hat Norhayati, and Mohmad Rouyan Nurazan. 2014. "ANALISA KELEMAHAN KEMAHIRAN MENULIS BAHASA ARAB DALAM KALANGAN PELAJAR UNISZA." In Prosiding Seminar Pengajaran Dan Pembelajaran Bahasa Arab 2014.

Ratnaningtyas, Oktavia. 2015. "Pembelajaran Menulis Bahasa Arab Di Program Khusus Perkuliahan Bahasa Arab (Pkpba) Universitas Islam Negeri Malang." Jurnal Penelitian Dan Kajian Keislaman Desemer.

Rofian, Mohamad, Ismail Ahmad, Redzaudin Ghazali, Khairatul Akmar, Abdul Latif, Phd Jabatan, Pengajian Bahasa, et al. 2016. "KERANGKA PEMBINAAN MODUL KEMAHIRAN MENULIS KARANGAN BAHASA ARAB UNTUK PENUTUR BUKAN ARAB DI IPTA MALAYSIA." In SEMINAR ANTARABANGSA AKIDAH, DAKWAH DAN SYARIAH 2016 (IRSYAD 2016).

Setiadi, Syamsi. 2017. "PENINGKATAN KETERAMPILAN KITABAH ARABIYAH MAHASISWAMELALUI METODE TUTOR SEBAYA." Jurnal Al Bayan: Jurnal Jurusan Pendidikan Bahasa Arab. https://doi.org/10.24042/albayan.v9i1.1094.

Simamora, Susi Susanti, and Tangson Rudolf Pangaribuan. 2017. "PENGARUH MODEL PEMBELAJARAN INKUIRI TERHADAP KEMAMPUAN MENULIS TEKS CERITA PENDEK OLEH SISWA KELAS VII SMP NEGERI 1 SIBABANGUN KABUPATEN TAPANULI TENGAH TAHUN PEMBELAJARAN 2014/2015." Kode: Jurnal Bahasa 6 (4). https://doi.org/10.24114/kjb.v6i4.10835.

Sitti Kuraedah. 2015. “Aplikasi Maharah Kitabah Dalam Pembelajaran Bahasa Arab.” Al-Ta'dib.

Thu'aimah, Rusydi Ahmad. 2010. Al Mahārat Al Lughowiyah Mustawayātuhā Tadrīsuhā Shu'ubātuhā. Kairo: Dar Al Fikr.

Wahab, Muhbib Abdul. 2015. "Pembelajaran Bahasa Arab Di Era Posmodern." ARABIYAT: Jurnal Pendidikan Bahasa Arab Dan Kebahasaaraban. https://doi.org/10.15408/a.v2i1.1519. 